\title{
INTERPRETASI KEPERCAYAAN DEBITUR KKM CENTRAL SANTOSA FINANCE CABANG SURABAYA
}

\author{
Wilma Cordelia Izaak, Hesty Prima Rini \\ Fakultas Ekonomi dan Bisnis, \\ Universitas Pembangunan Nasional Veteran Jawa Timur, Surabaya
}

\begin{abstract}
\begin{tabular}{l|l} 
Abstrak & Tujuan dari penelitian ini adalah untuk menganalisis dan menginterpretasikan pengaruh
\end{tabular} perceived quality serta perceived value terhadap kepuasan dan loyalitas konsumen Kredit Kepemilikan Motor (KKM). Pengambilan sampel penelitian menggunakan teknik purposive sampling dengan sampel terdiri dari 67 debitur KKM di Central Santosa Finance Cabang Surabaya. Data penelitian dianalisis menggunakan metode Partial Least Square (PLS). Hasil penelitian menunjukkan bahwa perceived quality berpengaruh positif signifikan pada loyalitas melalui kepuasan, perceived value berpengaruh positif signifikan terhadap loyalitas, baik secara langsung maupun tidak langsung melalui kepuasan. Namun, perceived quality tidak berpengaruh langsung pada loyalitas. Hasil penelitian tersebut mengimplikasikan bahwa perusahaan harus terus meningkatkan layanannya untuk mempertahankan kepercayaan, kepuasan, dan loyalitas konsumennya.
\end{abstract}

Kata Kunci: $\quad$ kepuasan, loyalitas, perceived value, perceived quality.

\begin{tabular}{l|l} 
Abstract & $\begin{array}{l}\text { The purpose of this study is to analyze and interpret the effect of perceived quality and } \\
\text { perceived value on consumer satisfaction and loyalty. The research sample was taken using } \\
\text { a purposive sampling technique with the sample consisting of } 67 \text { debtors of motorbike } \\
\text { ownership credit at the Central Santosa Finance Surabaya. The research data were } \\
\text { analyzed using Partial Least Square (PLS) method. The results showed that perceived } \\
\text { quality had a significant positive effect on loyalty through satisfaction, and perceived value } \\
\text { had a significant positive effect on loyalty, both directly and indirectly through satisfaction. } \\
\text { However, perceived quality did not have a direct effect on loyalty. These results implied that } \\
\text { the company should continuously improve its service quality to maintain customer trust, } \\
\text { satisfaction, and loyalty. }\end{array}$
\end{tabular}

Keywords: $\quad$ loyalty, perceived quality, perceived value, satisfaction.

Fakultas Ekonomi dan Bisnis

UPN Veteran Jawa Timur

E-mail: wilma.izaak.mnj@upnjatim.ac.id, hestyprimarini.mnj@upnjatim.ac.id 


\section{Pendahuluan}

Pertumbuhan ekonomi Indonesia mengalami perbaikan setiap tahunnya, walaupun diperkirakan melambat sejak tahun 2016 namun dengan pertumbuhan ekonomi yang demikian, semakin menyuburkan lahan investasi dan makin banyak investor pada berbagai sektor usaha jasa menanamkan modalnya untuk mendapatkan keuntungan. Salah satu jenis investasi yang terus berkembang adalah investasi di bidang leasing atau kredit kepemilikan motor melalui suatu lembaga pembiayaan. Saat ini masyarakat Indonesia dihadapkan pada kenyataan semakin maraknya perusahaan jasa dalam sektor kredit kepemilikan kendaraan bermotor dan sektor perbankan, sehingga menuntut masyarakat agar lebih cermat dan bijak dalam memutuskan pilihan pada perusahaan jasa lembaga pembiayaan yang sesuai dengan kebutuhan mereka dan kemampuan mereka.

Dengan adanya peraturan Bank Indonesia nomor 18/16/PBI/2016 tentang pembiayaan kendaraan bermotor maka diharapkan bagi lembaga pembiayaan mampu meningkatkan permintaan domestik dalam persaingan yang sangat kompetitif ini, sehingga akan menjaga stabilitas makroekonomi. Hal ini disebabkan banyaknya bank yang beroperasi di Indonesia baik yang beroperasi secara lokal maupun yang beroperasi berskala internasional. Kenyataan lain yang mendukung persaingan perbankan di Indonesia adalah, masyarakat Indonesia saat ini sangat menikmati gaya hidup yang konsumtif, sehingga semakin banyak kebutuhan yang harus terpenuhi melalui produk barang maupun jasa khususnya kendaraan bermotor.

Lembaga pembiayaan yang bekerjasama dengan bank adalah salah satu perusahaan di sektor jasa yang menawarkan fasilitas untuk memudahkan pemenuhan gaya hidup konsumtif tersebut. Dewasa ini, lembagalembaga pembiayaan yang mampu bertahan melewati masa krisis moneter maupun lembaga-lembaga pembiayaan yang baru beroperasi mulai berlomba-lomba untuk memberikan layanan yang terbaik kepada nasabahnya atau debiturnya melalui berbagai macam produk perbankan seperti produk kredit kepemilikan motor dan produk kredit motor bekas. Di tahun 2018 industri perbankan akan memasuki persaingan berskala global yang lebih berat, dan hal itu merupakan suatu tantangan yang harus dihadapi dan ditangani oleh bank untuk dapat memberikan kontribusi dalam pembangunan bangsa melalui pemberdayaan ekonomi masyarakat luas. Perubahan yang terjadi dalam lingkungan eksternal, persaingan yang semakin ketat dan perilaku masyarakat selaku konsumen yang lebih selektif dalam melakukan penilaian terhadap produk dan mengembangkan sejumlah pertimbangan dalam perilaku pembeliannya. Kualitas pelayanan menjadi komponen utama karena produk-produk utama lembaga pembiayaan salah satunya yaitu kredit, yang merupakan suatu penawaran yang tidak berbeda dan pelayanan jasa perbankan yang juga mudah ditiru (Aviliani dan Wilfridus, 2017). Oleh karena itu persaingan akan sangat dipengaruhi oleh kemampuan lembaga pembiayaan memberikan pelayanan terbaik yang bermutu dibandingkan pesaingnya. Kepuasan debitur ditentukan oleh kualitas produk dan layanan yang dikehendaki sehingga jaminan kualitas menjadi prioritas utama. Untuk kepuasan debitur terhadap layanan, ada dua hal pokok yang saling berkaitan erat yaitu persepsi terhadap kualitas layanan (perceived value and perceived quality) dan kepuasan atas kualitas layanan. Konsumen selalu menilai suatu layanan yang diterima, dibandingkan dengan apa yang diharapkan atau diinginkan oleh mereka. (Grönroos, 2014).

Kepuasan nasabah harus disertai dengan loyalitas nasabah/debitur. Kepuasan nasabah/debitur menyangkut apa yang diungkapkan tentang persepsinya (perceived value dan perceived quality) terhadap layanan kredit kepemilikan sepeda motor yang diperoleh dari lembaga pembiayaan tersebut. Sedangkan loyalitas berkaitan dengan apa yang dilakukan nasabah/debitur setelah berinteraksi dalam suatu proses layanan kredit kepemilikan sepeda motor. Hasil evaluasi konsumen akan mengarah pada kepuasan (satisfaction) ataupun ketidakpuasan (dissatisfaction), selanjutnya kepuasan dapat menimbulkan loyalitas (Lovelock, et al. 2014), dan dapat mendorong 
perilaku konsumen yang diinginkan (Cronin dan Steven, 2012), yaitu minat beli ulang konsumen pada produk dan jasa perusahaan. Hal ini menunjukkan secara teoritis maupun empiris, kepuasan dan loyalitas nasabah dipengaruhi oleh perceived value, yaitu suatu penilaian terhadap persepsi tentang keuntungan yang akan didapat oleh nasabah sehubungan dengan citra perusahaan dan harga produk yang ditawarkan (Li, 2013), yang kedua adalah perceived quality yaitu penilaian subyektif nasabah terhadap suatu layanan yang diharapkan sesuai dengan persepsi atau harapan nasabah. Pada perceived quality terdapat lima aspek utama kualitas layanan, (1) reliability; (2) tangibles; (3) emphaty; (4) responsiveness; dan (5) assurance. Konsep ini menyiratkan bahwa kepuasan nasabah/debitur saja tidaklah cukup, karena puas atau tidak puas hanyalah salah satu bentuk emosi, disamping itu loyalitas konsumen juga tidak kalah relevannya untuk dianalisis sebab sikap loyal akan timbul setelah mereka merasakan puas atau tidak puas terhadap layanan kredit kepemilikan sepeda motor yang diterimanya (Tjiptono, 2014:386).

Pada pasar kredit kepemilikan kendaraan bermotor baik yang beroda dua maupun beroda empat, lembaga pembiayaan memiliki beberapa jenis kredit yang umum ditawarkan kepada nasabah antara lain: kredit kepemilikan motor dan produk kredit motor bekas. Para investor di kawasan regional ataupun dunia melihat besarnya potensi pasar kredit terutama pada jenis kredit konsumtif kendaraan bermotor di Indonesia yang dikarenakan oleh besarnya jumlah penduduk di Indonesia, salah satu cara untuk mengakses unit kendaraan bermotor dari segi pembayaran adalah menggunakan produk KKM (Kredit Kepemilikan Motor) yang disediakan oleh bank-bank yang menjalin kerjasama dengan pihak leasing. Produk KKM adalah fasilitas pembiayaan kepemilikan kendaraan bermotor yang difasilitasi oleh lembaga pembiayaan. Di mana pihak lembaga pembiayaan akan membayar unit kendaraan yang dipilih konsumen kepada pihak leasing. Selanjutnya debitur akan mengangsur uang pembayaran kendaraan tersebut kepada pihak lembaga pembiayaan setelah melewati tahapan kroscek data debitur dan tahapan analisa kemampuan mengangsur debitur sehingga pada proses pengangsuran akan dapat dihindari terjadinya kredit macet. Oleh karenanya beberapa lembaga pembiayaan akan melihat kapasitas kredit yang telah diambil dan juga mempertimbangkan besaran dari kredit berjalan tersebut, jika terlalu besar maka akan riskan sekali dalam pelaksanaan kredit lancar.

Konsep loyalitas banyak digunakan sebagai pertimbangan di berbagai industri dan merupakan topik penelitian yang dominan dalam industri perbankan. Rumusan masalah pada penelitian ini adalah mengidentifikasi faktor-faktor yang mempengaruhi keputusan debitur untuk pengajuan kredit kepemilikan motor dari lembaga pembiayaan tertentu yang adalah aset penting bagi sebagian besar lembaga-lembaga pembiayaan apalagi jika digunakan dalam upaya untuk menarik debitur baru dan mempertahankan yang sudah ada. Tujuan dari penelitian ini adalah untuk mengidentifikasi apakah perceived value dan perceived quality melalui kepuasan debitur berpengaruh pada loyalitas debitur di Surabaya untuk pengajuan kredit kepemilikan motor di Central Santosa Finance Cabang Surabaya.

Dari beberapa definisi perceived value pada beberapa penelitian tentang nilai layanan yang ada, peneliti memilih definisi yang ditulis oleh Bettencourt dan Brown (2007) yang mengatakan bahwa perceived value adalah penialain konsumen atas nilai yang diciptakan serta mengingat pengorbanan dan manfaat yang diperoleh konsumen. Definisi tersebut diperkuat oleh Schiffman dan Kanuk (2007) yang menyebutkan bahwa perceived product value adalah suatu trade-off antara customer's perceived benefit atas suatu produk dengan perceived sacrifice baik monetary dan nonmonetary, seperti waktu, tenaga, atau psychological yang dibutuhkan untuk mendapatkan produk tersebut.

Kepuasan adalah perasaan senang atau kecewa seseorang yang disebabkan oleh kinerja suatu produk yang dirasakan dibandingkan dengan yang diharapkan (Kotler, 2013:36). Kepuasan dapat pula didefinisikan sebagai evaluasi alternatif terpilih memenuhi atau melampaui harapan, 
seperti yang dinyatakan Christoper,et al (1991) yang menyatakan bahwa kepuasan merupakan evaluasi pasca konsumsi yang menyatakan sesuai harapan atau tidak.

Konsep pertama yang membentuk loyalitas dari sisi perilaku adalah berdasarkan keuntungan yang didapat pelanggan, seperti yang dikutip dari teori Caceres dan Paparoidamis (2007) yang menyatakan bahwa Kelompok pemikiran pertama mendefinisikan kesetiaan dalam hal perilaku yang didasarkan pada jumlah akuisisi, dan yang kedua dalam hal sikap yang melibatkan preferensi konsumen dan kecenderungan terhadap merek. Berdasarkan pada dua aliran pemikiran tentang esensi kesetiaan, kesetiaan adalah konstruksi dua dimensi. Menurut teori tersebut dapat dikatakan bahwa terdapat dua dimensi yang membentuk loyalitas pelanggan, yaitu perilaku dan sikap.

Konsep "consumer perceived value" telah menjadi konsep penting dalam setiap kegiatan pemasaran, karena sangat erat berhubungan dengan keuntungan atau profits dan loyalitas atau loyalty (Sutanto,2008). Loyalitas mencerminkan sikap secara psikologis terhadap merek tertentu dan loyalitas dibagi menjadi 4 tahap yaitu kognitif, afektif, konatif, action. Dari segi kognitif, maka perceived value dapat diartikan sebagai berikut nilai persepsi kognitif mensintesis pengalaman makna dan keyakinan kolektif konsumen (Cronin dan Steven, 2012). Kualitas produk adalah keseluruhan gabungan karakteristik produk dan jasa dari pemasaran, rekayasa, pembuatan dan pemeliharaan yang membuat produk dan jasa yang digunakan memenuhi harapan pelanggan (Berry,2015). Kotler (2013:180) mengemukakan bahwa kualitas produk mempunyai hubungan yang sangat erat dengan kepuasan pelanggan karena kualitas produk dapat dinilai dari kemampuan produk untuk menciptakan kepuasan pelanggan.

Pada penelitian yang dilakukan oleh Anderson, dan Lehman (2014), ditemukan bukti empiris bahwa kualitas produk berpengaruh signifikan terhadap kepuasan konsumen.selain itu juga yang menyimpulkan bahwa kepuasan konsumen serta keunggulan produk mempunyai pengaruh positif terhadap kepuasan pelanggan.

\section{Metodologi}

Jenis penelitian yang dilakukan adalah penelitian eksplanatif, yaitu menguji hubungan antara tiga variabel penelitian (Arikunto, 2017), yakni perceived value dan perceived quality dengan kepuasan nasabah dan loyalitas nasabah/debitur KKM pada Central Santosa Finance cabang Surabaya.

Fokus penelitian ini adalah intepretasi hubungan-hubungan antara variabel (Singarimbun dan Sofian. 2012). Penelitian eksplanatif memerlukan perencanaan. Dengan metode eksplanatif, penelitian digunakan dengan jenis penelitian sensus. Penelitian sensus merupakan penelitian yang mengambil satu kelompok populasi sebagai sampel secara keseluruhan dan menggunakan kuesioner yang terstruktur sebagai alat pengumpulan data yang pokok untuk mendapatkan informasi yang spesifik (Christos, et al, 2012). Berdasarkan informasi tersebut, maka penelitian ini merupakan jenis penelitian dengan metode survei dengan bantuan kuesioner yang diberikan secara online, dimana respondennya adalah debitur yang telah menggunakan kredit kepemilikan motor. Populasi dalam penelitian ini adalah seluruh debitur kredit kepemilikan motor pada Central Santosa Finance cabang Surabaya yang sampai saat ini telah mengajukan KKM dengan jangka waktu kurang lebih 1 tahun berjalan dan mampu memberikan penilaian secara objektif terhadap kualitas pelayanan KKM terdiri dari 203 debitur yang merespon online questionnaire yang dibagikan.

Sampel adalah bagian dari populasi yang karakteristiknya hendak diselidiki, dan dianggap bisa mewakili keseluruhan populasi yang jumlahnya lebih sedikit daripada jumlah populasi (Sugiyono. 2015 :35). Responden dalam penelitian ini yaitu nasabah/debitur kredit kepemilikan motor pada Central Santosa Finance cabang Surabaya yang menjadi nasabah selama kurang lebih 1 tahun sampai dengan 3,5 tahun dan dinilai mampu memberikan penilaian secara objektif terhadap kualitas pelayanan KKM Central Santosa Finanace. Kriteria untuk sampel 
terpilih adalah debitur kendaraan roda dua pada Central Santosa Finance cabang Surabaya Timur, baik pria maupun wanita yang telah menjadi debitur KKM selama kurang lebih 1 tahun berjalan, tingkat pendidikan dan jenis pekerjaan tidak dibatasi. Dalam penelitian ini, penulis bermaksud mengintepretasikan hubungan antar variabel melalui penelitian survey. Penelitian survey yaitu "penelitian yang mengambil sampel dari satu populasi dan menggunakan kuesioner sebagai alat pengumpulan data yang pokok" (Singarimbun dan Sofian, 2012). Hasil yang didapat dengan tingkat signifikansi $10 \%$ sehingga didapat jumlah sampel sebesar 67 responden.

\section{Teknik Analisis Data}

Metode yang digunakan pada penelitian ini adalah PLS dengan pertimbangan karena adanya dua indikator yang berbeda dalam satu model yaitu indikator refleksif (pada konstruk perceived value, kepuasan dan loyalitas debitur) dan indikator formatif (pada konstruk perceived quality) dalam satu pemodelan persamaan struktural.

\section{Hasil dan Pembahasan}

\section{$\underline{\text { Hasil }}$}

Lamanya waktu pengajuan yang dijalani oleh responden ada kaitannya dengan perilaku, sebab perilaku individu akan menggambarkan tingkat kepercayaan konsumen dalam mengambil keputusan untuk pengajuaan kembali pada CS Finance atau tidak, data responden berdasarkan waktu pengajuan responden dapat dilihat pada tabel dibawah ini.

Tabel 1. Tabel Responden Berdasarkan Lama Pengajuan KKM

\begin{tabular}{ccc}
\hline $\begin{array}{c}\text { Lama Pengajuan } \\
\text { KKM }\end{array}$ & Jumlah & Prosentase (\%) \\
\hline$>3$ tahun & 11 & 16,42 \\
$2-3$ tahun & 18 & 26,87 \\
$1-2$ tahun & 23 & 34,33 \\
$<1$ tahun & 15 & 22,39 \\
Total & 67 & 100 \\
\hline
\end{tabular}

Sumber: data primer diolah 2018

Berdasarkan data tabel 1, dapat dilihat bahwa mayoritas responden nasabah KKM Central Santosa Finance telah mengambil tenor pada tahun pertama sampai dengan kedua yaitu sebanyak 23 responden atau 34,33\%, responden pada jangka waktu tenor 2 sampai dengan lebih dar 3 tahun masing 18 dan sebelas orang dengan prosentase $26,87 \%$ dan $16,42 \%$ dan pada tenor kurang dari tahun sebanyak 15 orang dengan prosentase $22,39 \%$.

Tabel 2. Tabel Responden Berdasarkan Kemampuan Mengangsur Melalui Pendapatan

\begin{tabular}{ccc}
\hline Pendapatan & Jumlah & Prosentase (\%) \\
\hline > Rp. 15 Juta & 14 & 20,90 \\
Rp. 5 Juta - Rp. 15 & 36 & 33,73 \\
Juta & & \\
< Rp. 5 Juta & 17 & 25,37 \\
Total & 67 & 100
\end{tabular}

Sumber: data primer diolah 2018

Berdasarkan data pada tabel 2 dapat diketahui bahwa sebagian besar responden dalam penelitian ini memiliki kemampuan mengangsur melalui pendapatan setiap bulannya sebesar Rp.5 juta hingga Rp.15 juta dengan jumlah sebanyak 36 orang atau sebesar 33,73\%, kemudian responden yang mempunyai pendapatan kurang dari Rp.5 juta sebanyak 17 orang atau sebesar 25,37\%, sedangkan yang memiliki pendapatan diatas Rp.15 juta sebanyak 14 orang atau sebesar $20,90 \%$.

\section{$\underline{\text { Analisis Data }}$}

Uji validitas bertujuan untuk mengukur sejauh mana alat ukur tersebut mampu mengukur apa yang hendak diukur. Tingkat signifikansi pada penelitian ini adalah $(p) \leq 0,05$ atau koefisien korelasi hitung ( $r$-hit) $\geq$ koefisien korelasi tabel ( $r$-tabel) maka instrumen tersebut dikatakan valid. Kehandalan diukur dengan nilai composite reliability, konstruk reliabel jika nilai composite reliability di atas 0,70 maka indikator disebut konsisten. dalam mengukur variabel latennya.

Sesuai hasil analisis data pada penelitian ini maka ke 4 hipotesis penelitian ini adalah sebagai berikut:

Hipotesis 1 : perceived quality (x2) berpengaruh positif signifikan terhadap loyalitas debitur (y2) melalui kepuasan debitur (y1). 
Perceived Quality berpengaruh terhadap Kepuasan Debitur memiliki hasil koefisien path sebesar 0,6069 , dapat diterima dimana nilai T-Statistic $=5,4594$ lebih besar dari nilai $\mathrm{Z} \alpha=0,10(10 \%)=1,645$, sehingga Signifikan (Positif). Kepuasan debitur berpengaruh terhadap loyalitas debitur memiliki hasil dengan koefisien path sebesar 0,5445, dapat diterima dimana nilai T-Statistic $=4,7435$ lebih besar dari nilai $\mathrm{Z} \alpha=0,10(10 \%)=1,645$, sehingga Signifikan (Positif). Maka hipotesis 1 diterima.

Hipotesis 2 : percieved quality (x2) berpengaruh positif signifikan terhadap loyalitas debitur (y2).

Dengan koefisien path sebesar 0,1358, TIDAK dapat diterima dimana nilai $\mathrm{T}$-Statistic $=$ 0,9887 lebih kecil dari nilai $\mathrm{Z} \alpha=0,10(10 \%)=$ 1,645 , sehingga Non Signifikan (Positif). Maka hipotesis 2 ditolak atau tidak dapat diterima.

Hipotesis 3: perceived value (x1) berpengaruh positif signifikan terhadap loyalitas debitur (y2) melalui kepuasan debitur (y1)

Perceived Value terhadap Kepuasan Debitur memiliki hasil koefisien path sebesar $-0,1175$, TIDAK dapat diterima dimana nilai T-Statistic $=0,8714$ lebih kecil dari nilai $\mathrm{Z} \alpha=0,10(10 \%)$ $=1,645$ sehingga Non Signifikan (Negatif).

Namun kepuasan debitur berpengaruh terhadap loyalitas debitur memiliki hasil dengan koefisien path sebesar 0,5445 , dapat diterima dimana nilai T-Statistic $=4,6435$ lebih besar dari nilai $\mathrm{Z} \alpha=0,10(10 \%)=1,645$, sehingga Signifikan (Positif). Maka hipotesis 3 ditolak.

Hipotesis 4: perceived value (x1) berpengaruh positif signifikan terhadap loyalitas debitur (y2).

Seperti data yang tertera pada tabel 3 maka dengan koefisien path sebesar 0,1561, dapat diterima dimana nilai $\mathrm{T}$-Statistic $=1,9125$ lebih besar dari nilai $\mathrm{Z} \alpha=0,10(10 \%)=1,645$, sehingga Signifikan (Positif). Maka hipotesis 4 diterima.
Tabel 3. Tabel Path Coefficients

(Mean, STDEV, T-Values)

Origin Sampl Standa Standa T-

al e Mean rd rd statisti

Sampl Deviati error st

\begin{tabular}{cccccc} 
& $\begin{array}{c}\text { Sampl } \\
\mathrm{e}\end{array}$ & & $\begin{array}{c}\text { Deviati } \\
\text { on }\end{array}$ & error & $\mathrm{c}$ \\
\hline $\begin{array}{c}\text { Kepuas.Deb } \\
\text { itur (Y1) -> } \\
\text { Loyalitas }\end{array}$ & & & & & \\
Debitur & 0.5445 & 0.5584 & 0.1198 & 0.1198 & 4.7435 \\
& 29 & 88 & 47 & 47 & 16
\end{tabular}

(Y2)

\begin{tabular}{|c|c|c|c|c|c|}
\hline $\begin{array}{l}\text { Percieved } \\
\text { Quality } \\
\text { (X2) -> }\end{array}$ & 0.6069 & 0.6153 & 0.1114 & 0.1114 & 5.4594 \\
\hline $\begin{array}{l}\text { Kepuas.Deb } \\
\text { itur (Y1) }\end{array}$ & 73 & 78 & 04 & 04 & 07 \\
\hline $\begin{array}{l}\text { Percieved } \\
\text { Quality } \\
\text { (X2) } \rightarrow\end{array}$ & & & & & \\
\hline $\begin{array}{l}\text { Loyalitas } \\
\text { Debitur } \\
\text { (Y2) }\end{array}$ & $\begin{array}{c}0.1358 \\
60\end{array}$ & $\begin{array}{c}0.1349 \\
93\end{array}$ & $\begin{array}{c}0.1722 \\
38\end{array}$ & $\begin{array}{c}0.1722 \\
38\end{array}$ & $\begin{array}{c}0.9887 \\
92\end{array}$ \\
\hline Percieved & & & & & \\
\hline $\begin{array}{c}\text { Value (X1) - } \\
>\end{array}$ & $\begin{array}{c}- \\
0.1175\end{array}$ & $\begin{array}{c}- \\
0.1113\end{array}$ & 0.1209 & 0.1209 & 0.8714 \\
\hline $\begin{array}{l}\text { Kepuas.Deb } \\
\text { itur (Y1) }\end{array}$ & 14 & 36 & & & \\
\hline $\begin{array}{c}\text { Percieved } \\
\text { Value (X1) - }\end{array}$ & & & & & \\
\hline $\begin{array}{c}\text { > Loyalitas } \\
\text { Debitur(Y2 } \\
\text { ) }\end{array}$ & $\begin{array}{c}0.1561 \\
51\end{array}$ & $\begin{array}{c}0.1593 \\
57\end{array}$ & $\begin{array}{c}0.0861 \\
52\end{array}$ & $\begin{array}{c}0.0861 \\
52\end{array}$ & $\begin{array}{c}1.9125 \\
07\end{array}$ \\
\hline
\end{tabular}

Sumber: data primer diolah 2018

Pembahasan

Perceived Quality Terhadap Loyalitas

Hasil uji menunjukkan bahwa perceived quality tidak berpengaruh secara langsung terhadap loyalitas, artinya semakin tinggi penilaian debitur terhadap daya tanggap, empati dan bukti langsung pada CS Finance cabang Surabaya dalam menangani proses KKM tidak mempengaruhi sikap nasabah secara langsung untuk melakukan pengajuan kembali (repeat order) pada CS Finance.

Begitu juga sebaliknya semakin rendah penilaian perceived quality debitur akan daya tanggap, empati dan bukti langsung pada CS Finance cabang Surabaya dalam menangani proses KKM tidak mempengaruhi debitur secara langsung dalam merekomendasikan ke orang lain sebagai bentuk loyalitas debitur KKM pada CS Finance. Hasil ini tidak sejalan dengan penelitian Grönroos (2008) yang 
menemukan hubungan langsung antara perceived quality dengan loyalitas.

\section{Perceived Quality Terhadap Kepuasan}

Berdasarkan hasil pengujian hipotesis yang telah dilakukan untuk menganalisis pengaruh perceived quality pada debitur KKM CS Finance cabang Surabaya, diperoleh hasil bahwa penilaian debitur atas rate cicilan dan keleluasan proses cicilan KKM berarti semakin tinggi pula penilaian debitur atas kualitas KPR Mandiri cabang maka akan tinggi pula kepuasan debitur KKM CS Finance secara langsung dalam merekomendasikan ke orang lain sebagai bentuk loyalitas pada CS Finance. Hasil ini sesuai dengan hasil penelitian $\mathrm{Li}$ (2013) yang menyatakan bahwa terdapat hubungan yang signifikan antara perceived quality terhadap kepuasan dan loyalitas, sehingga variabel kepuasan mampu berperan sebagai variabel intervening terhadap loyalitas debitur KKM CS Finance cabang Surabaya.

Melalui 3 dimensi pembentuk variabel laten perceived quality (responsiveness, emphaty dan tangibles) memperkuat pengaruh perceived quality atau penilaian nasabah secara kualitas memberikan kontribusi yang besar secara tidak langsung melalui kepuasan sebagai variabel interveningnya, dan hasil penelitian ini sesuai dengan penelitian Bloemer et al. (1998) yang menemukan adanya hubungan tidak langsung antara perceived quality terhadap loyalitas debitur melalui kepuasan debitur.

Pengaruh Perceived Value Terhadap Loyalitas

Berdasarkan hasil pengujian hipotesis yang telah dilakukan untuk menganalisis pengaruh perceived value terhadap loyalitas debitur KKM Central Santosa Finance cabang Surabaya, diperoleh hasil bahwa perceived value berpengaruh secara langsung pada loyalitas debitur KKM, hal ini berarti semakin tinggi penilaian nasabah akan citra perusahaan dan biaya administrasi pada angsuran pertama KKM CS Finance maka akan tinggi pula loyalitas debitur KKM CS Finance dalam mengambil sikap untuk melakukan repeat order KKM Central Santosa Finance cabang Surabaya, sebaliknya semakin rendah perceived value pada nasabah berarti rendah pula loyalitas yang ditentukan oleh tinggi rendahnya penilaian debitur akan biaya administrasi di angsuran pertama KKM CS Finance. Hasil ini sesuai dengan konsep "consumer perceived value" yang telah menjadi konsep penting dalam setiap kegiatan pemasaran, karena sangat erat berhubungan dengan keuntungan atau profits dan loyalitas atau loyalty (Monsef, et al. 2012).

\section{Perceived Value Terhadap Kepuasan}

Hasil pengujian hipotesis yang telah dilakukan untuk menganalisis pengaruh perceived value terhadap loyalitas melalui kepuasan debitur KKM Central Santosa Finance cabang Surabaya, diperoleh hasil bahwa perceived value tidak berpengaruh terhadap kepuasan debitur KKM Central Santosa Finance cabang Surabaya, yang berarti bahwa penilaian positif nasabah terhadap citra dan biaya administrasi pada angsuran pertama KKM CS Finance belum mampu memenuhi harapan debitur, dimana sebagian responden menjawab dalam kuesioner bahwa responden merasa denda keterlambatan pengambilan BPKB dan denda pinalti yang dikenakan oleh pihak CS Finance dalam KKM masih sangat tinggi, sehingga responden merasa tidak puas, namun hal ini tidak sejalan dengan teori Grönroos (2008).

yang mengatakan bahwa suatu perceived value yang tinggi tidak selalu berhubungan dengan biaya administrasi yang relatif rendah, karena mungkin saja suatu produk dengan penilaian yang tinggi dapat memiliki biaya yang tinggi. Seperti dalam penelitian Sutanto (2008) menunjukan bahwa perceived value hanya berpengaruh secara langsung terhadap loyalitas, dan tidak memiliki pengaruh yang signifikan terhadap kepuasan debitur KKM Central Santosa Finance cabang Surabaya.

\section{Kesimpulan}

Berdasarkan hasil pengujian-pengujian terhadap hipotesis yang telah diajukan sebelumnya dapat disimpulkan bahwa perceived value debitur KKM Central Santosa Finance cabang Surabaya, mampu meningkatkan loyalitas debitur KKM Central Santosa Finance cabang Surabaya, melalui 
penilaian debitur akan citra dan biaya administrasi pada angsuran pertama KKM CS Finance.

Perceived value nasabah debitur KKM Central Santosa Finance cabang Surabaya pada kepuasan atas keleluasaan dalam proses pencicilan dan rate cicilan yang rendah pada KKM Central Santosa Finance belum mampu mendorong debitur untuk melakukan repeat order pada Kredit Kepemilikan Motor Central Santosa Finance.

Perceived quality debitur KKM Central Santosa Finance cabang Surabaya atas sikap marketing sales dalam melayani debitur proses administrasi persiapan aplikasi kredit dengan cepat sebelum persetujuan, kesesuaian jadwal transaksi dengan kebutuhan debitur dan kemudahan untuk mencapai lokasi kantor pelayanan mampu meningkatkan loyalitas dan mau merekomendasikan KKM Central Santosa Finance kepada orang lain.

Keterbatasan pada penelitian ini adalah data pada penelitian ini hanya terbatas pada cabang Central Santosa Finance cabang Surabaya Timur. Diharapkan untuk penelitian yang akan datang untuk kembali dapat melakukan pembuktian variabel ini dalam kasus yang sama dengan menambah variabel lainnya dan dengan menggunakan metode yang berbeda agar hasilnya dapat dijadikan suatu kebijakan positif pada perusahaan sejenis.

\section{Daftar Referensi}

Anderson, E., Fornell, C. dan Lehman, D., 2014. Customer Satisfaction, Market Share dan Profitability: Finding from Sweden. Journal of Marketing, vol 58 (July), P.53-66.

Arikunto, Suharsimi. 2017. Prosedur Penelitian Suatu Pendekatan Praktek. Rineka Cipta. Jakarta.

Aviliani dan Wilfridus. 2017. Membangun Kepuasan Pelanggan Melalui Kualitas Pelayanan. Usahawan No.5 TH.XXVI.

Berry, L. L. 2015. Relationship marketing of services-growing interest, emerging perspectives. Journal of the Academy of marketing science 23 (4), 236-245.
Bettencourt, L. A. and Brown, S. W. 2007. Contact employees: Relationships among workplace fairness, job satisfaction and prosocial service behaviors. Journal of retailing 73 (1), 39-61

Caceres, Ruben Chumpitas dan Paparoidamis, Nicholas G. (2007). Service Quality, Relationship Satisfaction, Trust, Commitment and Business-to-Business Loyalty. European Journal of Marketing, Vol. 41 No.7/8. p. 836867.

Christoper, Payne dan Ballantyne. 1991. Relationship Marketing: Bringing Quality, Customer Service, and Marketing Together. Oxford. Butterworth Heinemann.

Christos C. Frangos, Konstatnos C. Frangos, Ioannis Sotiropoulos, Giannis Manolopoulos dan Aikaterini C. Valvi. 2012. Factors Affecting Customers Decision for Taking out Bank Loans: A Case of Greek Customers. Journal of Marketing Research \& Case Studies. Technological Educational Institute of Athens, Greece.

Cronin J.Joseph Jr. and Steven A.Taylor. 2012. Measuring Service Quality: A Re-examination and Extension. Journal of Marketing. July. Pp 55-68.

Grönroos, C. 2008. Service Management and Marketing: A Customer Relationship Management Approach. Second Edition. Chichester: Wiley and Sons.

Kotler, Philip. 2013. Marketing Management. Hal. 36. Eleventh Edition. New Jersey. Pearson Education.

Li, Jiao. 2013. Factors Affecting Customer Satisfaction And Customer Loyalty Toward Belle Footwear Company In Lanzhou City, Gansu Province of The People's Republic of China. IQSR Journal of Business and Management, Vol 14, Issue 2: 41-48.

Lovelock, Christoper,et al. 2014. Service Marketing :An Asia Pacific and Australian Perspective. $3^{\text {rd }}$ Edition. Frenchs Forest, NSW:Pearson Education Australia.

Monsef, Seyed Mahmoud Shabgoo; Mirabi, Vahidreza dan Vazifehdust,Hossein. 2012. Designing a Model for Explaining Customer Loyalty towards Banking Services in Iran (Case Study: Guilan Province). J. Basic. Appl. Sci. Res., Text Road Publication Scientific Research.

Schiffman dan Kanuk. 2007 Consumer Behavior, 9th ed. Prentice Hall.

Singarimbun, Masri dan Sofian Effendi. 2012. Metode Penelitian Survai. Jakarta: LP3ES. 
Sugiyono. 2015. Metode Penlitian Bisnis. Alfabeta: Bandung.

Sutanto, Jeanne Ananti. 2008. Pengaruh Service Quality Dan Perceived Value Terhadap Kepuasan Dan Loyalitas Konsumen Apartemen Di Kota Surabaya.

Tjiptono, Fandy. 2014. Strategi Pemasaran. Andi : Yogyakarta. 